\title{
Unlocking the Relationship between Entrepreneurship and Socioeconomic Integration
}

\author{
A study based on Nepali entrepreneurs in Lisbon, Portugal*
}

Biswash Praja

Erasmus Mundus, Masters in Advanced Development in Social Work, University of Lincoln, UK biswash.chepang@gmail.com

\begin{abstract}
This research project uses immigrant entrepreneur's perspectives on how entrepreneurship has influenced or facilitated in integration processes in host country. The study is based on Nepali immigrants engaged in entrepreneurship in Lisbon. Semi structured interview was used to interpret the narratives of the conversation with the respondents, which is coded into themes using thematic analysis. Twelve Nepali entrepreneurs were interviewed who owned small or medium scale business ventures in Lisbon. Being Nepali as well as migrant here in Portugal, enabled the researcher to reflect, analyse and interpret insider perspective for the study which controls the possible limitations of understanding the social milieu of the respondents during the study process. Social capital theory was used to analyse immigration, and entrepreneurship start-ups in host country. As a whole, it has been found out that, the entrepreneurial ventures helps Nepali immigrants to integrate in the host societies by facilitating them in easy adjustment process from the period of arrival until they settle down. The implications of this research are useful for local authorities in host country to further strengthen bonds between immigrants and host society through entrepreneurship. The social capital that is evident in community can be strength for authorities to support in establishing entrepreneurial ventures for Nepali immigrants.
\end{abstract}

Keywords: Immigrants, Entrepreneurship, Socioeconomic Integration, Nepali Entrepreneurs, Social Capital

\section{Introduction}

Immigrants' population has been rising in developed countries and Portugal is not spared from the trend. Persistent rising trend of immigrants to developed countries has been one of the major concerns for integration in host countries (Abranches \& Di Sciullo et al, 2008). According to International Organization for Migration (IOM), one fifth (22\%) of the total population in Portugal are immigrants (Oliveira, 2010; IOM, 2015). Emigration of Portuguese is considered as one of the major factors driving the immigration rate in the country (Justino, 2016).

Rise in immigrants' population poses opportunities as well as challenges to the host countries. Integration of new-comers is crucial for efficient socio-economic development of the host country (Goodman, 2010). Although Portugal ranks second in the migrant integration policy index (MIPEX) indicator after Sweden (MIPEX, 2015) there is no formalized monitoring system in Portugal to assess integration of immigrants. There are several discourses of integration strategies and measuring integration of immigrants in host society. Some considers integration as process of socialization in the host society (Barou, 2014), other defines integration process as engaging in host country's labour market (Entzinger \& Biezeveld, 2003; Ladygina \& Kharchuk, 2008; Ager \& Strang, 2008; Goodman \& Wright, 2015; Maxwell, 2017). Some emphasizes on learning language as major component in integration (Delander et al., 2005). Integration is necessary for immigrants as well

Review History: First manuscript submitted Aug 23, 2018; Submission of revised version Nov 6, 2018; Accepted Nov 14, 2018.

* This paper is adapted from thesis submitted for the partial fulfilment of Erasmus Mundus Masters on Advanced Development in Social Work, University of Lincoln, UK by Biswash Praja on June 11, 2018. 
as host society. Integrating immigrants helps to avoid stigmatization of migrants, prevent negative feelings in host society (Entzinger \& Biezeveld, 2003). Integration is crucial in overcoming present rising issue of religious conflicts attacks and several other conflicting social issues in the world (Wiesbrock, 2011).

In recent days, entrepreneurship has become popular among immigrants. Immigrants are more probable to initiate new business in the host nation than the native population (Desiderio \& Mestres-Domènech, 2011; Blume \& Ejrnæs et. al, 2009; Hou \& Wang, 2011; Kerr \& Kerr, 2016; Hou and Wang 2011). More than one fourth of the immigrants are self-employed in Portugal, Ireland, and Spain (Van Tubergen, 2005).

There are considerable number of Nepali immigrants in Portugal (Dahal, 2016; Oliveira \& Gmes, 2017) and many of them are engaged in entrepreneurship, such as hotels, restaurants, grocery shops and other service-oriented business. There is dearth of literatures related to Nepali immigrants and their integration in the foreign countries. No single study so far has been done on Nepalese immigrants engaged in entrepreneurial activity and their process of integration within Portuguese society in Lisbon. Therefore, the present study aims to find out the socio-economic integration process of Nepali entrepreneurs in Lisbon, Portugal.

\section{Theoretical framework: Social capital theory}

Putnam's social capital theory constructed by bonds, trusts, reciprocity in society is used as theoretical lens to analyse three dynamics including; immigration process, entrepreneurship establishment and integration in host society through social capital in this study. Social capital is one of the old concept that has been influential since 1990's. Putnam, Evans and Bourdieu during 90's are pioneers in explaining social capital theory. Several interdisciplinary fields ranging from sociology, economics, political science and education has been extensively using it in explaining their outcomes (Bick, 2010). Putnam (2001) states networks, and associated norms of reciprocity as central ideas in social capital. The value is generated within the circle for the people in the circle. Social capital is one kind of unique bond that is generated within alike gender, ethnicity, religious groups and so on within specific area (Bick, 2010). These networks help in cooperation and coordination for mutual benefit which helps in linking and connecting with the society that they are living (Bick, 2010; Jung, 2017). "Social capital refers to the norms and networks that enables people to act collectively" (Woolcock \& Narayan, 2000: 3). Social capital is characterized by trust, tolerance and reciprocity (Coleman, 1988) and this benefits through network. This further facilitates in creation of human capital within the network that people possesses (Coleman, 1988). Similarly, Conduluci, (2014) states social capital as the 'social glue' that holds the society together. Social capital is an intangible asset that emerge from social interactions, social networks, norms, trusts, good will and respects (Conduluci, 2014). This also acts as instrumental role in socio economic adaptation processes in the host society (Marger, 2001). This helps each other to confront social issues in society such as poverty, crime, mitigating disasters and resolve disputes (Cheung \& Kam, 2010). Social capital has power to bring the cohesion from the weaker section of society as well, which becomes strength within the community (Granovetter, 1998). Hence linking these micro levels with the macro section of society is widely used theoretical framework in today's social sciences.

\section{Research design}

This is a qualitative study and it brings out informed perspective on how entrepreneurship facilitates in socioeconomic integration process for immigrants. The main motive to use qualitative method in this study is for gaining indepth information in a non-directed way which is more open ended and contains more reflective based life experiences of individuals (Shaw \& Gould, 2001; Edwards \& Holland, 2013). Engel \& Schutt (2013) states the use of qualitative research is to explore, describe and evaluate through the participants' social world. This approach is useful in understanding the lives of participants, and aspects of their experiences through an interactive process (Edwards \& Holland, 2013). This approach enables researchers to know their experiences and how they interpret their social life in their own environment (Edwards \& Holland, 2013). The researchers interpret the findings by placing themselves in the researched participants' shoes (Denzin \& Lincoln, 2005). Qualitative research further enables researchers to be sensitive according to the contextual factors by understanding the symbolic dimension in the research process (Bryman \& Bryman et al, 2012). 


\section{Participants}

Total of 12 participants were selected who were originally from Nepal and had started enterprise on their own. To bring out the inclusive ideas, different sectors of business were selected ranging from restaurants, hotels, groceries, handicraft shops and saloon. A benchmark was set to select the participants for instance, one must have a legal status here in Portugal, have started a business and tentatively operated business lesser than ten years. Setting benchmark would avoid the biases that could arise in selecting participants (Biernacki \& Waldorf, 1981). Selecting participants having their business running for less than ten years was to get fresh experience of immigrant entrepreneurs and to find out how it helps in initial phases of integration process in host society. Snowball approach was used to find out the entrepreneurs in Lisbon to collect their views and experiences. This approach is especially applicable for the hidden population in a large group through connections, social networks between each other (Browne, 2005). The interview was carried out using saturation strategy; conducted an interview until the point where additional interview was no longer required as no new information are received from the respondent (Guest \& Bunce et al., 2006; Walker, 2012). Having relatively lesser amount of sample size enabled the researcher to analyse interview in in-depth way (Maxwell, 2008). This also preserves the individuality of each in their analyses (Maxwell, 2008). This further enables the researcher to understand how events, actions and meanings are shaped by their individual unique experience in their circumstances.

First field visit was conducted to see, observe, and meet Nepali entrepreneurs at their own business setting. Semi structured interview was conducted using native language; Nepali as a means of communication between participant and interviewer after preparation of interview guide which is attached in appendix section. Use of semi structured interview is "flexible and powerful tool" that captures the voices and meaning of their experience (Rabionet, 2011). Open-ended questions enabled the participants to express their own opinion and further give an opportunity for the researcher to probe and go in-depth based on the research objective (DiCicco-Bloom \& Crabtree, 2006). This method of data collection further considers interviewees as experts in their own. It enables to understand the events, situations and actions participants are involved in how it influences their behaviour (Maxwell, 2008). Semi structured interview further enables to co-create meanings and reconstructing perception and events of experience (DiCicco-Bloom \& Crabtree, 2006).

Thematic analysis was used as one way of identifying, analysing and reporting themes from the coded themes based on information from participants (Braun \& Clarke, 2006). Thematic analysis is a step by step and rigorous process that is trustworthy and provides insightful meaning with the thick description of analysis of data (Braun \& Clarke, 2006). The recorded interview is transcribed and coded into specific themes based on dimension of analysis. Use of semi structured interview in thematic analysis helped the researcher to analyse and find out the reality beyond lived experiences and get deeper insights.

\section{Findings and discussion}

Based on field visit, it was found that, there is an international market representing different countries in specific place; Martim Monez area in Lisbon. The participants shared their experiences of establishing their business ventures nearby their community within specified area which is particularly crowded by immigrants. Every participant had varied opinions of engaging in entrepreneurship. Some studies reveal, the reason for immigrants engaging in entrepreneurship being children and their intergenerational mobility (Raijman \& Tienda, 2000; Kloosterman, 2010; Skandalis \& Ghazzawi, 2014) which was reflected in Nepali community as well. However, there are several other pushing factors influencing immigrants into entrepreneurship.

The themes generated from twelve participants revealed that, engaging in entrepreneurship was to overcome oppression in the previous job. The terms such as low payment, work pressure, work timing, unfriendly work environment and unfair treatment from the employers in the previous work place made them start their own business. This notion is supported by several scholars where immigrant appear to engage in self-employment to overcome the challenges of underpayment, racial discrimination in the labour market and exclusion (see, Blancflower, 2000; Constant \& Shachmurove et.al. 2007; Mickiewicz \& Hart, 2017; Skandalis \& Ghazzawi, 
2014). The participant reflected the experience of working under someone's restaurant and did not want his staffs to feel the same. Use of terms like oppression, challenges, exploitation, workloads he had to undergo while working in others restaurant illustrates several difficulties faced by the respondents.

Based on reflections from participants, a person with strong economic status is more probable to participate in social events, gatherings, meetings and other ceremonies, which enables them to widen their network with the native population in a foreign society. Strong economic situation of immigrants helps them to enjoy freedom, increase their participation in social activities, which eventually supports them to feel home in the host nation (Ladygina \& Kharchuk, 2008). Self-employment helps in reducing poverty, increasing living standard and enhancing social well-being, which ultimately helps them in integrating into the host society (Grosu, 2015 and Sahin \& Nijkamp, 2007). This makes an individual independent of several day to day activities, which eventually assist individuals to engage and participate in the host society.

Nepali entrepreneurs seem to use their business as a means to enter into the society making a way to integrate in society through networks and interactions. It helped in interaction and exchange of knowledge, cuisine, and information help native population to gain from people with different cultural backgrounds. Such interaction and exchange activities help immigrant to be part of the native/host society (Eraydin \&TasanKok et al., 2010). Entrepreneurship activity assist immigrants to cross cuts the structural barriers, limited employment choices and exclusionary treatment in the labour market and support them to be accepted in the host society (Constant et al., 2007).

Having their own start-ups became a pathway for Nepali immigrants to familiarise with each other help build trust with the locals. According to Constant and Colleague (2007), "Self-employment is powerful instrument to integrate immigrants economically into the host country". Self-employment has been a way to adjust in society. They state this strategies as an antidote to unemployment by creating jobs. Entrepreneurial ventures promote intercultural competencies, active interaction with people of different cultures which plays crucial role in socialization in society (DimitraEvangelia, 2016).

Engaging in entrepreneurship is not just about starting a business and bringing new product to the market but is also to liberate oneself for freedom and autonomy (Verduijn \& Dey, 2014; Jennings \& Jennings et.al, 2016). The freedom that comes with entrepreneurship, helped respondents to live independent life without any external support from the government in the host country. Several scholars support the notion that entrepreneurship liberates oneself from social, technological or other institutional constraints (Verduijn \& Dey, 2014; Jennings \& Jennings et.al, 2016). This is considered integration as it helps to gain equal status as natives in the society where they live (Bartkeviciene \& Raudeliunaite, 2013). However, the illustrated ideas can be criticised as well depending on the time an entrepreneur is engaged in their business. Some may be profit oriented guided by monetary value rather than other elements.

\section{Perspectives on integration through entrepreneurship}

Migrants engaged in entrepreneurship contributes to the economy as entrepreneur as well as an employee (Desiderio \& MestresDomènech, 2011). This is one form of integration in the host society. Entrepreneurs not only employs themselves but also create employment opportunities for others (Entzinger \& Biezeveld, 2003; Ladygina \& Kharchuk, 2008; Euro stats, 2011; MIPEX, 2015).

Entrepreneurs or the business owners requires to communicate, negotiate, bargain for their product with wholesalers, retailers, customers in the market. Findings illustrates that participants were reinforced to learn host country language, which is one major indicator of integration for immigrant in the host society (Dimitra-Evangelia, 2016; Remennick, 2004; Dimitra-Evangelia, 2016). Numena (2008) illustrates the criteria for being integrated in society through family reunion in host country, where starting business eases this process in host society. Allowing immigrants to unite with their family connects immigrants with different individual, social and cultural aspects of life. This created sense of belonging in the society where they are living. Respondents further shared their experience of how owing a business facilitated in broadening social 
network in a community where they lived. Although, some participants shared their experience of excessive time spent on their business, networking was limited within their own community groups and not having time to socialise and interact in society, most of them shared their experience of positive impact of entrepreneurship that helped in integration process in society. Some authors support this notion that business and networking could limit the exposure of newly arrived individuals to integrate in the host society which may not necessarily integrate him in the host society (Perkins \& Hughey et al., 2002; Leonard, 2004; Martinovic \& Van Tubergen et al, 2009). Rather it might isolate and marginalise from the main stream society as the entire process of arrival to business start-up is dependent on fellow nationality. Inequality may exist within the community itself which might also isolate the individual with limited networking (Leonard, 2004; Farrell, 2007). This can rather be constraint in itself for individual's action and choices (Leonard, 2004). Farrell (2007) states that social capital may not necessarily be always positive which sometimes can be guided by selfinterest leading to oppression.

\section{Business venues as a space for 'informal organizations and a place to socialise}

Business venues of Nepali entrepreneurs is used as a space for meeting, socialisation and discussion among fellow nationality. It was found that, these informal organizations have been providing free language classes and job training as per the demand of the labour market in Lisbon to the Nepali citizens. The free training session enhanced the capability of Nepali immigrants in host society. This social capital benefitted individuals by increasing their possibilities to find jobs in the labour market especially, for those who cannot start small and medium scale firms on their own (Sanders \& Nee et al, 2002). Furthermore, entrepreneurs were found providing job and other logistics information like official registration process, locations etc. for the newly arrived immigrants. Participants shared their business venue as a place to meet, gather, socialize and share their stories of joys and sorrows. This plays significant role in enriching the affective commitment within the nationality and the Nepali community.

\section{Social capital, entrepreneurship and integration}

Despite being far away from home country, Nepali immigrants find someone to support especially in their initial days of arrival through family network, relatives, friends, same ethnic groups. The trusts, bonds, connections and reciprocity between each other enables to overcome most of the challenges that might come across in foreign countries (Sanders \& Nee et.al, 2002; Potocky-Tripodi, 2004; Hernández-Plaza \& Aloso-Morillejo et al, 2006; Eraydin \&TasanKok et al., 2010). Hence, the migrants who get the support from the established immigrants face less challenges in their process of adjustment in society. These available social networks help to overcome less explored challenges of entrepreneurship and unanticipated risks that might come across (Levitte, 2004). The bonding in the community bridge and link the natives in host society facilitating the process of integration.

Nepali immigrants who have the experience of operating business act as counsellor and mentor for other fellow nationality willing to start a venture. These informal networks and supports among themselves helps to integrate immigrants in host society. According to Farell (2007) social network and society plays major role in connecting beyond the community and providing platform to interact, participate and mix in the host society which is a major indication of integration in the host society. Furthermore, linking and bonding through informal networks help in confronting several problems and issues that comes across. Hence, it is necessary to establish the strong bond that is present within the community to the outer area of their community i.e. native inhabitants.

Summing up these findings, social capital and social network available in the community supported immigrants, since their arrival to establishment of their business including adjustment, fulfilling official procedures, finding jobs, residence and business registration in the host society. The business they owned further facilitated in integration process. Moreover, entrepreneurship facilitating family reunion, acquisition of language, broadening social networks, cultural exchange via business spaces sharing gradually helped in deeper localization process in the host society. The business venues worked as informal institutions such as parcel office, hostel, focal place to 
contact for fellow Nepali nationality and place to organize cultural events.

\section{Implication and recommendation for practice}

Immigrants engaging in entrepreneurial ventures not only strengthens the economic aspect but also helps in deeper localizations through ethnic enclaves which helps immigrants to fit in local environment (Zhou \& Liu, 2015). Hence this is one of the alternative path for integration of immigrants in host societies (Zhou \& Liu, 2015; Brozozowski, 2017; Batsaikhan \& Darvas et al, 2018).

The bonding, trusts, reciprocity between Nepali immigrants is found to be strong supporting each other in host society. The bonding among immigrants turns into tangible resources which helped poor communities to uplift overcoming limited resources they had in the community (Levitte, 2004). Embracing social capital could be one of the tool for professionals, agencies working with immigrants by utilizing the relationships of trusts, mutual caring and mutual support to each other (Nieman, 2014).

Proper coordination and collaboration between these informal networks of immigrants and local municipalities can be helpful in making integration plans. Proper support system for immigrants and their business brings economies and societies together (Thornton \& RibeiroSoriano et al, 2011). This could help them to know each other and can further seek support when needed. Local authorities can lobby with different actors and policy makers to design policies that favours immigrants and facilitate them to integrate in host society. Developing policy to support through their own network can be another recommendation for professionals working with immigrants to utilise the bonding available in the community.

Entrepreneurs can further be educated on local procedures, culture, markets etc. This can be done through community-based workshops where there is collaboration between internal and external actors. Further programs like setting up mentors as mentioned by Evansluong (2016) for the immigrants in the host country could link each other and provide a platform to learn from each other in the host society. Business support programs to raise capital, understanding bureaucracy of the governmental process, establishing contacts, providing training are some forms of support that could be provided to immigrants (Riddle \& Hrivnak et al, 2010).

\section{Conclusion and further research}

In a nut shell, entrepreneurship enables to make difference in societal perception towards social and cultural attitudes of immigrants like recognition, respect and friendly attitudes. These are also part of integration process in the host society. It is also necessary to first understand that immigrants are not super entrepreneurs (Naudé \& Siegel et al, 2017) but the ones who are engaged in entrepreneurship like Nepali immigrants in Portugal due to different circumstances or situations facilitated them in integration process in society. This research does not intend to exacerbate every immigrant to be entrepreneur but to develop policies for immigrants who are willing to do business on their own and train them to be entrepreneur.

However, one needs to be cautious about generalizing the findings with the overall immigrant populations as this could depends on the types of immigrant group (Tegene, 2015). Putnam's concept of social capital; where informal bonding and networking is present in certain immigrant groups not necessarily present in all immigrant groups. Entrepreneurship can be a comprehensive model to integrate immigrants in host society and this can be innovative strategy for local authorities to solve issues of social exclusion. Researcher would further recommend carrying out research on comparative analysis of informal supports and networking's among immigrants from different countries to generalise recommendation.

\section{References}

Abranches, M., Di Sciullo, L., Rosario, E. \& Santos, T. 2008, "Measuring Integration: the Portuguese Case. Regional Indicators of Social and Labour Market Insertion of Third Country Nationals", .

Ager, A. \& Strang, A. 2008, "Understanding integration: A conceptual framework", Journal of refugee studies, vol. 21, no. 2, pp. 166-191. 
Barou, J. 2014, "Integration of immigrants in France: a historical perspective", Identities, vol. 21, no. 6, pp. 642-657.

Bartkeviciene, A. \& Raudeliunaite, R. 2013, "Social Support Strategies for Immigrants: The Context of Social Work Practice in Lithuania", Journal of Arts and Humanities, vol. 2, no. 3, pp. 90.

Batsaikhan, U., Darvas, Z. \& Raposo, I.G. 2018, "People on the move: migration and mobility in the European Union", Blueprints.

Bick, E. 2010, "The Tal Law: A Missed Opportunity for "Bridging Social Capital” in Israel", Journal of Church and State, vol. 52, no. 2, pp. 298-322.

Biernacki, P. \& Waldorf, D. 1981, "Snowball sampling: Problems and techniques of chain referral sampling", Sociological methods \& research, vol. 10, no. 2, pp. 141-163.

Blanchflower, D.G. 2000, "Self-employment in OECD countries", Labour economics, vol. 7, no. 5, pp. 471-505.

Blume, K., Ejrnæs, M., Nielsen, H.S. \& Würtz, A. 2009, "Labor market transitions of immigrants with emphasis on marginalization and self-employment", Journal of Population Economics, vol. 22, no. 4, pp. 881-908.

Braun, V. \& Clarke, V. 2006, "Using thematic analysis in psychology", Qualitative research in psychology, vol. 3, no. 2, pp. 77-101.

Browne, K. 2005, "Snowball sampling: using social networks to research non-heterosexual women", International journal of social research methodology, vol. 8, no. 1, pp. 47-60.

Bryman, A. (2012). Social research methods. Oxford university press.

Brzozowski, J. 2017, "Immigrant Entrepreneurship and Economic Adaptation: A Critical Analysis", Entrepreneurial Business and Economics Review, vol. 5, no. 2, pp. 159-176.

Bryman, A. (2012). Social research methods. Oxford university press.

Cheung, C. \& Kam, P.K. 2010, "Bonding and bridging social capital development by social workers", Journal of Social Service Research, vol. 36, no. 5, pp. 402-413.

Coleman, J.S. 1988, "Social capital in the creation of human capital" in Knowledge and social capital Elsevier, , pp. 17-41.

Condeluci, A. (2014). Social capital and the power of relationships. [video] Available at: https://www. youtube.com/watch?v=qaBUV2J0ax4 [Accessed 10 Feb. 2018].

Constant, A., Shachmurove, Y. \& Zimmermann, K.F. 2007, "What makes an entrepreneur and does it pay? Native men, Turks, and other migrants in Germany", International Migration, vol. 45, no. 4, pp. 71-100.

Dahal, S. 2016, Perception and practice of gender among Nepalese in Portugal: a male perspective.

Delander, L., Hammarstedt, M., Månsson, J. \& Nyberg, E. 2005, "Integration of immigrants: The role of language proficiency and experience", Evaluation review, vol. 29, no. 1, pp. 24-41.

Denzin, N.K. \& Lincoln, Y.S., (2005), The discipline and practice of qualitative research (3rd ed. p3) California; Sage.

Desiderio, V. \& Mestres-Domènech, J. 2011, "Migrant Entrepreneurship in OECD Countries", .

DiCicco-Bloom, B. \& Crabtree, B.F. 2006, "The qualitative research interview", Medical education, vol. 40, no. 4, pp. 314-321.

Dimitra-Evangelia, P. 2016, The entrepreneurial activity of the immigrants in the municipality of Volos as an influence on social integration, University of Thessaly.

Edwards, R. \& Holland, J. (eds) 2013, What is qualitative interviewing?, 1st edn, Bloomsbury, London. Engel, R. J. \& Schutt, R. K., (2013) The practice of research in social work (3rd ed. p295), Los Angeles; Sage Entzinger, H. \& Biezeveld, R.L. 2003, Benchmarking in immigrant integration, European Research Centre on Migration and Ethnic Relations (ERCOMER), Rotterdam.

Eraydin, A., Tasan-Kok, T. \& Vranken, J. 2010, "Diversity matters: immigrant entrepreneurship and contribution of different forms of social integration in economic performance of cities", European Planning Studies, vol. 18, no. 4, pp. 521-543.

Eurostat. 2011. Indicators of Immigrant Integration. A Pilot Study 2011 Edition. Luxembourg: European Union. http://www.emnbelgium.be/publication/eurostat-study-indicators-immigrant-integration.

Evansluong, Q.V. 2016, Opportunity creation as a mixed embedding process: A study of immigrant entrepreneurs in Sweden.

Farrell, C. (2007). Thinking critically about social capital. Irish Journal of Sociology, 16(2), 27-49.

Goodman, S.W. 2010, "Integration requirements for integration's sake? Identifying, categorising and 
comparing civic integration policies", Journal of ethnic and migration studies, vol. 36, no. 5, pp. 753-772.

Goodman, S.W. \& Wright, M. 2015, "Does mandatory integration matter? Effects of civic requirements on immigrant socio-economic and political outcomes", Journal of Ethnic and Migration Studies, vol. 41, no. 12, pp. 1885-1908.

Granovetter, M.S. 1998, "The strength of weak ties", Non profit management and leadership, vol. 9, no. 2, pp. 153-171.

Grosu, R. 2015, "Dynamics of immigrant entrepreneurship in Romania", Economy of the region, , no. 2.

Guest, G., Bunce, A. \& Johnson, L. 2006, "How many interviews are enough? An experiment with data saturation and variability", Field methods, vol. 18, no. 1, pp. 59-82.

Hernández-Plaza, S., Alonso-Morillejo, E. \& Pozo-Muñoz, C. 2005, "Social support interventions in migrant populations", British Journal of Social Work, vol. 36, no. 7, pp. 1151-1169.

Herreros, F. \& Criado, H. 2009, "Social trust, social capital and perceptions of immigration", Political studies, vol. 57, no. 2, pp. 337-355.

Hou, F. \& Wang, S. 2011, "Immigrants in self-employment", Perspectives on Labour and Income, vol. 23, no. 3, pp. 3.

IOM. (2015). Global Migration Trends Factsheet | IOM's Global Migration Data Analysis Centre. [online] Available at: http://gmdac.iom.int/global-migration-trends-factsheet [Accessed 6 Dec. 2017].

Jennings, J.E., Jennings, P.D. \& Sharifian, M. 2016, "Living the dream? Assessing the "entrepreneurship as emancipation" perspective in a developed region", Entrepreneurship Theory and Practice, vol. 40, no. 1, pp. 81-110.

Jung, N. 2017, Economic Integration of immigrants in United States, University of Pittsburgh.

Justino, D. 2016, Emigration from Portugal: Old wine in new bottles? Migration Policy Institute, Transatlantic Council on Migration.

Kerr, S.P. \& Kerr, W.R. 2016, "Immigrant entrepreneurship", Harvard business school, .

Kloosterman, R. \& Rath, J. 2010, "Shifting landscapes of immigrant entrepreneurship", Open for Business, , pp. 101.

Kloosterman, R. \& Rath, J. 2001, "Immigrant entrepreneurs in advanced economies: mixed embeddedness further explored", Journal of ethnic and migration studies, vol. 27, no. 2, pp. 189-201.

Kontos, M. 2003, "Self-employment policies and migrants' entrepreneurship in Germany", Entrepreneurship \& Regional Development, vol. 15, no. 2, pp. 119-135.

Ladygina, O. \& Kharchuk, B. 2008, "Managing Integration and Immigration: Impellent Question of the European Union", .

Leonard, M. 2004, "Bonding and bridging social capital: Reflections from Belfast", Sociology, vol. 38, no. 5, pp. 927-944.

Levitte, Y. 2004, "Bonding social capital in entrepreneurial developing communities-survival networks or barriers?", Community Development, vol. 35, no. 1, pp. 44-64.

Marger, M.N. 2001, "Social and human capital in immigrant adaptation: The case of Canadian business immigrants", The Journal of Socio-Economics, vol. 30, no. 2, pp. 169-170.

Martinovic, B., Van Tubergen, F. \& Maas, I. 2009, "Changes in immigrants' social integration during the stay in the host country: The case of non-western immigrants in the Netherlands", Social science research, vol. 38, no. 4, pp. 870-882.

Maxwell, J.A. 2008, "Designing a qualitative study", The SAGE handbook of applied social research methods, vol. 2, pp. 214-253.

Maxwell, R. 2017, "Occupations, national identity, and immigrant integration", Comparative Political Studies, vol. 50, no. 2, pp. 232-263.

Mickiewicz, T., Hart, M., Nyakudya, F. \& Theodorakopoulos, N. 2017, "Ethnic pluralism, immigration and entrepreneurship", Regional Studies, pp. 1-15.

MIPEX, 2015. Migrant Integration Policy index. [Online]

Available at: http://www.mipex.eu/portugal [Accessed 28 March 2018].

Naudé, W., Siegel, M. \& Marchand, K. 2017, "Migration, entrepreneurship and development: critical questions", IZA Journal of Migration, vol. 6, no. 1, pp. 5.

Nieman, A. 2014, "Social capital and social development", Social Work/Maatskaplike Werk, vol. 42, no. 2. Numena, E (2008) The Portuguese context in Abranches, M., Di Sciullo, L., Rosario, E. and Santos, T., 2008. Measuring Integration: the Portuguese Case. Regional Indicators of Social and Labour 
Market Insertion of Third Country Nationals.

Oliveira, R, \& Gmes, N. (2017). Indicadores da integração de imigrante: Relatório Estatístico anual. Lisboa: Biblioteca Nacional de Portugal.

Oliveira, C.R. 2010, "The determinants of immigrant entrepreneurship and employment creation in Portugal", Open for Business, , pp. 125.

Perkins, D.D., Hughey, J. \& Speer, P.W. 2002, "Community psychology perspectives on social capital theory and community development practice", Community Development, vol. 33, no. 1, pp. 33-52.

Potocky-Tripodi, M. 2004, "The role of social capital in immigrant and refugee economic adaptation", Journal of Social Service Research, vol. 31, no. 1, pp. 59-91.

Putnam, R. 2001, "Social capital: Measurement and consequences", Canadian journal of policy research, vol. 2, no. 1, pp. 41-51.

Rabionet, S.E. 2011, "How I learned to design and conduct semi-structured interviews: An ongoing and continuous journey", The Qualitative Report, vol. 16, no. 2, pp. 563.

Raijman, R. \& Tienda, M. 2000, "Immigrants' pathways to business ownership: A comparative ethnic perspective", International migration review, , pp. 682-706.

Rath, J. \& Kloosterman, R. 2000, "Outsiders' business: A critical review of research on immigrant entrepreneurship", International Migration Review, , pp. 657-681.

Remennick, L. 2004, "Language acquisition, ethnicity and social integration among former Soviet immigrants of the 1990s in Israel", Ethnic and Racial Studies, vol. 27, no. 3, pp. 431-454.

Riddle, L., Hrivnak, G.A. \& Nielsen, T.M. 2010, "Transnational diaspora entrepreneurship in emerging markets: Bridging institutional divides", Journal of International Management, vol. 16, no. 4, pp. 398-411.

Sahin, M., Nijkamp, P. \& Baycan-Levent, T. 2007, "Migrant entrepreneurship from the perspective of cultural diversity", Handbook of research on ethnic minority entrepreneurship, , pp. 99-113.

Sanders, J., Nee, V. \& Sernau, S. 2002, "Asian immigrants' reliance on social ties in a multiethnic labor market", Social Forces, vol. 81, no. 1, pp. 281-314.

Semyonov, M., Raijman, R. \& Gorodzeisky, A. 2006, "The rise of anti-foreigner sentiment in European societies, 1988-2000", American Sociological Review, vol. 71, no. 3, pp. 426-449.

Shaw, I., and Gould, N. 2001, Qualitative research in social work, Introducing qualitative methods, SAGE Publications Ltd, London, [Accessed 10 June 2018], doi: 10.4135/9781849209694.

Skandalis, K.S. \& Ghazzawi, I.A. 2014, "Immigration and entrepreneurship in Greece: Factors influencing and shaping entrepreneurship establishments by immigrants", International Journal of Entrepreneurship, vol. 18, pp. 77.

Tegegne, M.A. 2015, "Immigrants' social capital and labor market performance: The effect of social ties on earnings and occupational prestige", Social Science Quarterly, vol. 96, no. 5, pp. 1396-1410.

Thornton, P.H., Ribeiro-Soriano, D. \& Urbano, D. 2011, "Socio-cultural factors and entrepreneurial activity: An overview", International small business journal, vol. 29, no. 2, pp. 105-118.

Van Tubergen, F. 2005, "Self-employment of immigrants: A cross-national study of 17 western societies", Social forces, vol. 84, no. 2, pp. 709-732.

Verduijn, K., Dey, P., Tedmanson, D. \& Essers, C. 2014, "Emancipation and/or oppression? Conceptualizing dimensions of criticality in entrepreneurship studies", International Journal of Entrepreneurial Behavior \& Research, vol. 20, no. 2, pp. 98-107.

Walker, J.L. 2012, "Research column. The Use of Saturation in Qualitative Research.", Canadian Journal of Cardiovascular Nursing, vol. 22, no. 2.

Wiesbrock, A. 2011, "The integration of immigrants in Sweden: a model for the European Union?", International Migration, vol. 49, no. 4, pp. 48-66.

Woolcock, M. \& Narayan, D. 2000, "Social capital: Implications for development theory, research, and policy", The world bank research observer, vol. 15, no. 2, pp. 225-249.

Zhou, M. 2004, "Revisiting ethnic entrepreneurship: Convergencies, controversies, and conceptual advancements", International migration review, vol. 38, no. 3, pp. 1040-1074.

Zhou, M. \& Liu, H. 2015, "Transnational entrepreneurship and immigrant integration: New Chinese immigrants in Singapore and the United States" in Immigration and Work Emerald Group Publishing Limited, pp. 169-201. 